\title{
RECORD KEEPING AS AN AID TO ENFORCEMENT
}

\author{
By Kate Holladay Claghorn, \\ New York School of Philanthropy.
}

The American public, having lately acquired the idea that social ills may be reached by legislation, has taken up the idea with such enthusiasm that the one thing immediately proposed when some special difficulty is brought to our attention, is to "pass a law." And the same enthusiasm, trickling through to legislatures, enables the said "law" to be passed with ease. Unfortunately, public attention seems to flag at this point. Having attained the immediate object, which in itself seems a wonderful advance upon our ancient tradition of individual responsibility, everything is thought to be accomplished.

As a matter of fact, the passing of the law is the beginning, not the end of a process of social remedy. It is merely the establishing of conditions for a social experiment. However carefully any matter of social reform has been thought out, it is impossible to lay down beforehand exactly the means to attain it, or to prophesy exactly the reactions that will take place for good or for ill, or the hindrances that will arise, in the complex conditions of our modern civilization.

But what would be thought of the chemist, who, after combining the elements of his experiment, cheerfully turned his back on them, leaving them to form the expected compound or blow up, as might happen!

Yet something of this sort is constantly being done by us. With regard to housing legislation there is one good reason for this procedure in that while housing evils are widespread throughout the country, and in communities of every size, housing laws, of any thoroughgoing description, have been enacted for only a few localities, mostly the larger cities, and in most of these so recently that the experiment may be said to be only just under way. In one case, however, the need of continued watching of the experiment was foreseen. That was in the New York City tenement house department organized in 1902 to carry out the provision of the tenement house act of 1901 . 
The method of testing an experiment is by observing and recording its results. And this was provided for in the tenement house department by the establishment of a bureau of records to collect and classify such observations.

It is obvious that a law will fail of its purpose, first, if not properly administered; secondly, if it does not meet new and unforeseen conditions that come to light in the course of its concrete application.

Altogether too little attention has been given to either of these points. If it is thrust upon public attention that a certain law is a failure, the only thing thought of is that it has been administered by "rascals" and the "rascals" must be "turned out." There is not usually much concrete evidence of bad administration available, or anything to show that the difficulties really arose from conditions of the problem itself, as is sometimes the case. Evidence along these lines the bureau of records of the New York tenement house department was organized to furnish, as well as to prevent bad administration and imperfect enforcement. The system adopted was devised by Mr. Lawrence Veiller, then first deputy commissioner under Commissioner Robert W. de Forest, and its usefulness has been proved by the fact that, throughout twelve years of changing administration, it has been found necessary to retain all of the essential features of the original scheme.

For the principal set of records the card system was adopted on account of its readiness of reference and general adaptability. A record was started for every building in the city under the jurisdiction of the department, and the plan was extended to include, for some particulars, the other buildings. Of tenements alone there were over 80,000 at the time of organization of the department; by 1912 the number had increased to over 103,000. These cards were filed according to street and number so that all the facts about one house could be found in one place, and the cards were of different colors for different sets of facts. One set consisted of the original reports of inspectors on conditions found in their inspections. Yellow cards were used for such reports. The tenement house law of 1901 is mandatory, prescribing in considerable detail what shall be done. For inspections to determine how far buildings conformed to the conditions prescribed, printed forms (cards 5 by 8 inches) were divised, indicating the conditions to be noted, with blank spaces to be filled with a check mark to show that the condition indicated 
existed, or with the word "Yes" or "No," or with a measurement. One form dealt with points to be noted in inspection for structural conditions in tenements built before the passage of the act; another, for structural conditions in newly built tenements. All new tenements are thoroughly inspected in course of construction and, when completed, comply with the law. The "new building" card is made out, however, to give a convenient record of its structure so that subsequent alterations may be detected, if any are made without filing plans with the department. Another printed blank card dealt with sanitary conditions, another with fire-escapes, another with basements. Each covered some important branch of the department's work, prescribed in certain sections of the law.

These cards are filled out in the field, by the inspector, and signed by him, so as to fix responsibility for the accuracy of the statements made. These printed blanks have several advantages. One is the saving of time in making out the report, a large part of which is printed on the card. Another is that the report is made in the same order by each inspector and the results may be clearly seen and compared. Still another is that, with a printed list of things to look for and to check as present or not present, the inspector is less likely to overlook anything and may be held to stricter accountability if he does so. To report conditions not provided for in any printed form, an unprinted yellow card is used, also signed by the inspector.

These cards when filled in are forwarded from the different bureaus of inspection to the bureau of records where there is no possibility of subsequent alteration by the inspector.

The primary use of these records is as a basis for orders to owners to remedy conditions in violation of law, and as evidence against owners in case of a suit. They are also useful as a check upon the work of the inspectors. In case the same or another inspector makes a subsequent inspection of the same premises, the results may be compared and inaccuracies or attempts at fraud may be discovered.

Another set of cards (white-in color) gives a summary of the exact order issued to the owner. As fast as any portion of an order is complied with, that portion is crossed off the summary. So that at any time may be seen just what the owner of a given house is legally liable for, and what work he has already done. This portion 
of the record is much used as a source of information by persons dealing in tenement property, to adjust prices equitably according to the amount of obligation for repairs, and so forth, attached to the property at a given time. Other city departments with a less modern system of records require from a week to ten days to give out such information; the tenement house department will furnish it in twenty-four hours. These "searches" as they are called, are in themselves a valuable aid in enforcement. If a buyer finds a building heavily encumbered with "violations" he presses the seller to comply with them before the sale, which the latter usually hastens to do. These white forms are kept permanently on file in the bureau of records, but inspectors are given duplicates of them for use in reinspection. These duplicates, between reinspections, are themselves kept in a separate file.

Still another set of cards belonging to the main file in the bureau of records are those recording deaths, cases of tuberculosis, and cases of contagious disease other than tuberculosis, as they occur, in tenement houses. These are chocolate color, buff and pink, respectively. The general purpose of these is to correlate housing conditions and health conditions. Their immediate use in departmental practice has been to indicate houses where special inspections should be made. The reporting of a death or case of disease which brought the number above the ordinary, was the signal for an immediate, careful inspection, to remove any illegal condition that might have contributed to the unusual death or sickness rate. This set of cards also affords a basis for a study of the causal relation between housing conditions of different sorts and health, which would be most valuable as a guide to further legislation, or possible modification of the present code, with sufficient material and sufficient time to work it out. Up to the present time, however, the records have not been thoroughly studied in this light.

All the cards for each house are preceded in the main file by an index card, blue in color. On this card are entered, from reports forwarded from different divisions, the dates of complaints and their serial numbers, the fact that inspections of different kinds, indicated by symbols, such as " $I$ " for structural, " $U$ " for sanitary, and so on, have been made, date and serial number of orders issued to owners, date of dismissal of orders, serial number of plans filed for new buildings and alterations, with dates of filing, approval and issuance of 
certificate of completion, date and serial number of permits to occupy basement, date of replies to requests for information as to violations, and such other items of information as are needed in department procedure. This index card thus affords a bird's eye view of the entire history of a tenement house, so far as the department has been concerned with it. It also, and this is an important feature, provides a list of the other card records which should be on file. The inspector's original report cards, kept in the file, are numbered to correspond with the violation orders which are based upon them, and also have a serial number of their own. The white cards, summarizing the violation orders, also bear their respective violation numbers. These numbers again appear on the blue index card as a record of action. Every number shown on the blue card then, referring to a violation order calls for two cards in the file,-an inspector's report card of some sort and a summary of the order. In like manner, every number on the index card refers to some report or paper concerning the house, which should be on file. This system of checks makes it extremely difficult to tamper with the records successfully for the sake of destroying evidence or for any other reason.

A dishonest inspector may wish to suppress evidence which might incriminate him. An unscrupulous owner might want to clear the record of his property by altering that record rather than by doing the work ordered. Any attempt in that direction involves getting hold of so many links that some are usually omitted, so that discrepancies in the record appear and the fraud is quickly detected. In one notable case a lawyer had arranged with a contractor, for a substantial fee, to secure the early dismissal of violation orders on certain properties. The contractor afterwards claimed that the service he thought he was paying for was simply a little acceleration in unwinding what many considered the unnecessary "red tape" of the department.

The lawyer's method, however, was this. He secured confederates in four divisions of the department, each of whom was responsible for destroying or altering some piece of evidence. Cards had to be abstracted from several different files, certain stamped entries had to be made, index cards had to be taken away from the department that false entries might be typewritten thereon, letters on departmental letterheads were written, and signed by a purloined 
signature-stamp, and other operations gone through. Notwithstanding the care and cleverness with which this plan was organized, the alterations made in the records and the discrepancies arising, soon attracted attention, and put the department on the track of the fraud. An indictment for forgery was found against the offending lawyer, and the result was a salutary warning against further practices of like nature.

In practice, then, this complete system of records has been of great service in assuring the success of the social experiment involved in the tenement house law by assisting in its enforcement. It helps materially in keeping the inspectors up to their work, and in checking "graft." Anything that makes grafting difficult, and blocks the way of temptation, is naturally a help to the morals of the inspection force. It also helps enforcement on the side of compliance by the owners. With a complete record of actual conditions before them, heads of departments can make their claim against the owner with assurance that the claim is just. Many times the owner who is disinclined to admit the justice of these claims, on being confronted with evidence, is obliged to agree that they are just. These exact records not only enable the officials to resist the pressure of all sorts of demands, but form a means in turn of checking the efficiency of their administration. For these records, under the law, are "public records," to be at the public disposal under proper regulation.

The records have also proved useful in testing the results of the "experiment"-otherwise the tenement house law. They have afforded material to show the different effects upon housing conditions of the different provisions; to show hindrances in popular feeling, or in attendant circumstances, economic and social, to carrying out the law; and to show unforeseen practical difficulties. This material has been freely utilized to secure proper modification of the law, and to resist unjust attacks upon it, and has been of the greatest value.

When the tenement house department was organized, no one knew even how many tenements there were. Now a running account of the tenements is kept, so that at any time one may know how many there are, whether of the improved type erected under the law of 1901, or of the older types; how much living accommodation each class affords, what are the structural conditions in each, how they are distributed, how rapid is the progress of improvement, and so on. 
A field of study that should be worked more thoroughly is that of the relation between housing and public health. The health record gives the basis for that, but attempts to carry on such studies have not been very successful, partly because sufficient material had not been accumulated. By this time, however, the record covers a period of eleven years, and with a carefully framed plan, some valuable results ought to be secured.

To make the best use of records along the lines indicated, they must be continuous, and they must be comparable. A gap in the record may leave out the very link you are most anxious to find. When the records are not kept in the same way at one time as another, comparisons are not possible and we cannot trace any line of improvement or deterioration of conditions, of increase or decrease of efficiency. It is a vexing problem, often, whether to let a poor system of records stand, and keep the possibility of comparison, or to improve it, having a better system but losing comparability.

And of course in establishing a system of records there must always be an intelligent adjustment of means to ends. The New York system, applying to over 100,000 tenement houses, would be absurd for a town of two or three thousand dwellings, where one man is both inspector, keeper of records and chief of department. Furthermore, in any place, big or little, any system of records is absolutely useless unless the records are made with intelligence and used with intelligence. No "system" by itself can secure either of these essential points. If records are made by inspectors, these must have training and sense enough to know how to set down their observations accurately and clearly. The "practical" man, who has been a plumber, or a builder, or a trade worker of any kind and is supposed to be especially fitted for housing inspection by reason of his concrete knowledge of conditions, is likely to fail on this very point. It is surprising to find what mistakes can be made in recording matters of observation, as for example, in merely enumerating "dark rooms" - a term clearly and expressly defined in the law, and in departmental regulations.

Inspectors should not only be required to pass an examination for appointment, but should be carefully trained after appointment. This means that their chiefs and supervisors should be capable of training them and keeping them up to a standard.

It is of course perfectly useless and wasteful to heap up an elab- 
orate record of conditions that is not used by anyone. This is the defect in many elaborate systems installed-there is no one around with sufficient intelligence to draw any conclusions from them. In installing a system it should be considered who is to use it, and for what purpose, and the system should be adjusted accordingly. Much of our proposed reform in municipal accounting fails in this way. A system is adopted requiring a large staff of experts and much expense to keep it going. The "experts" may be drawn from an ordinary clerk's or bookkeeper's eligible list, and unable to keep up the work properly, the reluctant heads of departments upon whom it has been forced will not make use of it, and the general public cannot. Its only use is for professional investigators, and its value will depend upon the judgment they exercise, which is not always the greatest. 